\title{
Polo Santillán, M. A. (2016). El silencio del rey mono. Autoconocimiento y ética. Lima, Fondo Editorial de la Universidad Nacional Mayor de San Marcos
}

El silencio del rey mono es un libro pequeño en formato y extensión, pero gigante y ambicioso en propuestas y reflexiones. Reflexiones sobre un atractivo cruce disciplinar que Miguel Polo denomina "antropoética". Dicha disciplina combina las metáforas y frases filosóficas orientales con las sentencias filosóficas griegas. La ética socrática es el punto de partida y disparador que por momentos yuxtapone y engarza muy bien con sabiduría oriental y budista en torno a la ética del autoconocimiento. Notamos también que Miguel Polo desliza una tímida advertencia a la perspectiva helenocéntrica y, por ende, eurocéntrica que considera la ética del autoconocimiento como un tópico exclusivamente occidental; sin embargo, sigue atrapado en ella pues para el autor no hay otra manera de pensar la ética del autoconocimiento sin recurrir a Sócrates y los griegos. Por esa razón es que, a la postre, la cita de textos orientales es complementaria o simplemente marginal en toda la obra. El título se debe a que el mono ha sido una de las metáforas budistas para la mente, cuyo poder dirige toda la vida humana, por eso es el rey. El silencio del rey mono es la posibilidad de la mente humana de autoeducarse, de estar quieta y observarse a sí misma, de estar en paz y ser sabia. El libro contiene un prólogo que resume muy bien el contenido del texto, una atractiva introducción, cinco capítulos de mediana extensión y un epílogo a manera de balance. El prólogo fue escrito por el filósofo mexicano Mauricio Beuchot a la medida de la obra y del autor, es decir: sobrio, circunspecto, aristotélicamente prudencial al momento de pensar, sentir, vivir y escribir, pues no cae en los extremos, sea por defecto o por exceso, del abstraccionismo puro y principista o del activismo ético militante. Beuchot rastrea e identifica en la obra una propuesta ética en clave socrática, al mismo tiempo que señala una ética basada en la conjunción: teoría (especulación) y praxis (acción). Por último, 
Beuchot reconoce que el principal mérito de este libro consiste en acudir no solo a la tradición filosófica griega y occidental, sino también a la milenaria tradición religiosa y filosófica oriental; así, en esa dirección — pensamos nosotros-, Miguel Polo intenta tímidamente distanciarse del heleno-centrismo ético, pero no lo logra porque Sócrates sigue siendo su principal referente para pensar el autoconocimiento del hombre y la ética hoy en pleno siglo XXI.

El capítulo I, “Ética del autoconocimiento de Sócrates”, se subdivide en cuatro secciones. 1) Ética del autoconocimiento. Sostiene que la doctrina socrática está basada en el precepto délfico "conócete a ti mismo" que se produce a través del diálogo; en cambio, el autoconocimiento en Heráclito y los orientales es una vía de introspección pura (p. 19). En consecuencia, la mayéutica socrática en tanto autoexploración es sumamente relevante y presupone cuatro elementos: a) la existencia de un ser otro u otredad; b) el ejercicio de la palabra; c) la autoconciencia; d) genuina indagación por medio de la palabra. 2) Ética socrática en la apología. Diálogo donde se expone la misión socrática a través de cuatro temas: a) "Ética y sabiduría": Sócrates cree que Dios lo ha puesto como modelo de sabiduría, pero esta no estriba en la cantidad de saberes que posee, sino en la actitud frente a la hybris (orgullo por el saber). Por eso dirá: "solo sé que nada sé". b) "Autoconocimiento y ética": el gnothi seauton además de búsqueda, también es principio de sabiduría y criterio para discernir lo bueno de lo malo. c) "Ética y finalidad del ser humano": una de las finalidades era la perfección del alma por medio del conocimiento de uno mismo. En consecuencia, surge en Sócrates una misión filosófico-religiosa que consiste en moralizar la polis ateniense a través del autoconocimiento. d) "Ética y política": Sócrates tiene un concepto negativo de la política institucionalizada, por eso cree que la polis ya no es un referente moral por excelencia, sino debe serlo la propia conciencia moral (p. 27). 3) La ética socrática en Critón. Diálogo donde se le pide que escape de la cárcel, justamente en ese contexto se muestra la personalidad moral de Sócrates y los principios que orientan su vida. Basándose en Ruso Delgado, el profesor Polo propone 4 principios: a) búsqueda de buenas razones, b) no solo vivir sino 
vivir bien, c) unidad de las virtudes, d) no faltar a la justicia. 4. Autoconocimiento e intelectualismo. Polo se opone a una interpretación aristotélica que considera a Sócrates como el fundador de una técnica que busca la definición universal. Por el contrario, la mayéutica tiene como objetivo la purificación de alma y su respectivo cuidado. De esta forma, la ética socrática sigue siendo filosófica-religiosa antes que científica o lógica (p. 32).

El capítulo II, "Tres vías en el conocimiento de sí mismo", se subdivide en una breve introducción y cuatro secciones. En la introducción, el autor desliza una tímida advertencia a la perspectiva helenocéntrica y, por ende, eurocéntrica que considera la ética del autoconocimiento como un tópico exclusivamente occidental (p. 19). Por el contrario, para Miguel Polo, se trata de un tópico cuya genealogía es relativa, discontinua, heterogénea y contingente. 1) La vía racionalista da prioridad al aspecto intelectual en el conocimiento de sí mismo y da origen a tres formas de conocerse: a) "Superficial", porque se queda en lo que otros dicen de la vida humana; b) "Filosófica", porque se pretende vivir según doctrinas filosóficas; c) "Científica", porque la psicología, la neurociencia o la genética en tanto discursos científicos nos ofrecen un concepto del hombre y, por ende, un modelo de vida; d) "Crítica" porque se acentúa en la dimensión racional o cognitiva por sobre la vivencia de nuestro propio ser y sentir (p. 39). 2) La vía de la interioridad. Aquí el hombre se coloca como "objeto" de estudio, explorando las múltiples dimensiones de su ser. Miguel Polo propone tres vertientes: a) Sujeto ontológico (de los hindúes): se trata de conocer nuestra subjetividad limitada para lograr nuestro ser pleno. Actitud que tiene presupuestos metafísicos como la creencia de que existe un Yo superior que habita en nuestro ser. b) Fenomenología budista: actitud que consiste en poner entre paréntesis la subjetividad para darse cuenta de lo que es. c) Subjetivismo individualizado: se trata de un autoconocimiento que afirma la individualidad y rompe con la trascendencia (p. 43). 3) La vía de la alteridad. Afirma el carácter relacional de la vida humana cuyos antecedentes antiguos, modernos y contemporáneos son: Confucio, Sócrates, Hegel, Krishnamurti, Taylor, Honneth. Esta vía presenta 
tres vertientes: a) "El encuentro dialógico griego": el diálogo (Sócrates, Platón, Epicuro) tiene una función exploratoria, donde por medio de la palabra se busca tomar conciencia de las ideas erradas. b) "El otro como espejo": ha sido Krishnamurti, pensador indio, quien continúa la vía socrática en nuestra época. "Propone que lo primero es estar alerta desde lo externo a lo interno, lo que permitiría no autoegañarnos" (p. 48). c) "La exigencia del otro": Lévinas traza un camino para el autoconocimiento, donde la centralidad se haya en el afuera, en el otro. d) "El otro dentro de un horizonte": Taylor abre una perspectiva para el autoconocimiento al sostener que la identidad se constituye intersubjetivamente, lo cual implica asumir un horizonte de pertenencia. 4). Hacia una ética del conocimiento de sí mismo. Advierte que las excesivas ramificaciones y tipologías representan tan solo un mapa. Reconoce que las propuestas de autoconocimiento estaban acompañabas de un carácter práctico, pues no tendría valor si es meramente teórico. De este modo, el autoconocimiento no era solo una operación intelectual de clasificar los componentes de la mente. Se trata de tener una experiencia vital, afectiva, personal e impersonal hacia un sentimiento de realización (p. 51).

El capítulo III, “Ordenando la ética”, está planteado a manera de balance sobre la filosofía moral en la historia del pensamiento europeo y anglosajón. Allí Miguel Polo no vacila en criticar por segunda vez a la ética analítica contemporánea o metaética, por su afán de claridad y rigurosidad lógica del lenguaje moral y por desatender el compromiso y prácticas morales necesarias (p. 55). Luego, propone una justificación cultural y filosófica antes de desarrollar las tres dimensiones de la ética (sapiencial, virtuosa y meditativa) que podría ayudarnos a orientar mejor nuestras vidas personales y colectivas. a) Justificación cultural: ambos (el hombre ilustrado como el de sentido común) están sumergidos en el mismo problema de no saber cómo articular su propia existencia; por esa razón, Miguel Polo se pregunta por las posibilidades de una ética que responda a las exigencias de los nuevos tiempos. b) Justificación filosófica: la tarea del filósofo consiste en reconstruir la ética en un sentido más abarcador y de fácil acceso a las masas, pues notamos que ha alcanzado un nivel de abstracción y especialización ininteligibles para los 
profanos (p. 57). 1) La dimisión sapiencial. Consiste en lo que Aristóteles llamaba phrónesis o sabiduría práctica que comprendía tanto razones como pasiones, pero también la imaginación, especialmente de los mundos posibles en el marco de una comunidad; dicha sabiduría práctica necesita revisar los pensamientos y no darlos por sentados y verdaderos. 2) La dimensión virtuosa. Apunta a la renovación de los modos de vida cotidianos (miserables, codiciosos, egoístas, violentos que originan luchas y guerras). 3) La dimensión contemplativa. Señala "todo el campo que pertenece a la observación, la atención, el darse cuenta, la mirada atenta, la percepción alerta, el silencio contemplativo, es decir, meditar...”. En efecto, el silencio contemplativo nos vincula, nos hace sentir que pertenecemos a un mundo más allá del mental. Por último, Miguel Polo propone una "ética con sentido renovado" donde el autoconocimiento sea la matriz de toda filosofía moral y al mismo tiempo destaque sus tres dimensiones interrelacionadas (sapiencial, virtuosa y contemplativa). Así, tendría efectos positivos en tres ámbitos: la vida personal y social, la ética filosófica y la educación.

El capítulo IV, "Fenomenología y hermenéutica de la atención”, se divide en cinco partes. 1)La hermenéutica de la atención: la India clásica. Esquemáticamente podemos decir, según Miguel Polo, que la enseñanza principal del Buda histórico se resume en tres conceptos centrales: sabiduría (pañna), moralidad (sila) y concentración (samadhi); la atención pertenece al último grupo, por eso sostiene y da sentido a la sabiduría y la moralidad. 2) Hermenéutica de la atención: la tradición occidental. Se subdivide en dos partes: a) "Las huellas del pasado": comienza con Aristóteles para quien la filosofía nace con el asombro (taumazein) y que podría interpretarse como ir más allá de la mirada superficial; el "asombro" se convirtió en búsqueda y contemplación del modelo ideal, lo que marcaría la praxis religiosa y política (p. 78). En consecuencia, la "vida contemplativa" de los filósofos tendrá mayor valor que la "vida activa". También estuvo presente subrepticiamente en la filosofía contemporánea con Heidegger, que permanece fiel al ser como evento. b) "La huella del presente": se trata de una perspectiva que busca articular la contemplación con la praxis. Un ejemplo pertinente podría 
ser para Polo el caso de los teólogos y filósofos de la liberación que fijan su mirada en el pobre de Latinoamérica. 3) Krishnamurti y la actualización de la atención. Filósofo indio del siglo XX, distingue dos niveles de conciencia: a) percepción de mundo y de nuestro cuerpo y b) ser consciente de las respuestas mentales que nunca son la realidad como él decía: "la palabra no es la cosa", "el mapa no es el territorio". Krishnamurti contrapone el "yo" y el ver. El "yo" es el no-ver y, por ende, no puede ser consciente. 4) Recuperación de la atención. Consiste en asumir una conciencia del todo o experiencia de toda la realidad, es decir, pensar en las posibilidades antropo-éticas de una vida atenta; naturalmente, la atención tiene compromisos psicológicos y ontológicos, pero también implica un sentido de vida y praxis que pueda conducirnos en situaciones concretas. 5) La mente y la percepción de los objetos. Basándose en el Buda, Polo intenta explicar cómo la mente percibe su objeto. Resulta que la mente está en "piloto automático" y "parlotea" frente a un objeto percibido y la dinámica de estas actividades es que son procesos condicionados, dualistas y reactivos.

El capítulo V, "La dificultad de escuchar al otro", se subdivide en cuatro secciones y una introducción. En la introducción, el autor reconoce que hemos heredado una tradición racionalista (desde Parménides hasta Hegel) donde se menosprecia los sentidos y las sensaciones y se privilegia la razón. Por ese motivo intenta invertir esa situación y acabar con esos privilegios. También nos recuerda que su enfoque es antropoético, es decir, la ética necesita de "una antropología abierta que se interroga por el hombre y no aquella que ofrece una idea acabada del hombre" (p. 97). 1) El problema de la escucha, el problema de los sentidos. Sostiene que el "escuchar", "ver" u "observar" eran metáforas de la «inteligencia» que los filósofos han utilizado desde épocas clásicas. Para el autor, específicamente con Platón se manifiesta la subvaloración de los sentidos para acceder a la verdadera realidad. Posteriormente, con Descartes las sensaciones se convierten en simples mecanismo (hilos y cables) del cuerpo. Ahora identifica un contraste entre la actitud griega y judía con respecto a la primacía de los sentidos. En los griegos clásicos predomina la vista y en los judíos el escuchar, 
“después de todo a Dios se le escucha, no se le ve". Mientras que los griegos buscan un saber superior a través de un proceso ascendente, los judíos practican el escuchar con implicancias éticas y políticas, pues se trata de actuar y vivir en el mundo (p. 98). Por último, el autor cree que el cristianismo sintetiza estas dos actitudes y aspectos del conocimiento, pues a dios se le ve y se le escucha. 2) Fenomenología de la escucha. Escuchar y observar significa exponerse, dejar afectar, "despertar la sensibilidad y desde ahí crear el mundo de la vida de la que ambos participamos". Desde el punto de vista histórico, la modernidad europea con Descartes identificará el yo con los subjetivo y surge el sujeto moderno como: "yo soy una cosa que piensa". Para descentrar la ética del "yo pienso" cartesiano y moderno, el autor emplea el concepto interser como el lugar propio de nuestro ser ("yo soy por lo tanto tú eres") del sabio budista Thich Nhat Hanh. También nos habla de la existencia como proceso participativo. 3) La escucha total. Para el autor, siguiendo a Krishnamurti, "no se trata solo de escuchar palabras, sino de escuchar e ir más allá de ellas, es decir, escuchar todo". La escucha total es tanto de lo externo e interno, de la totalidad del ser. 4) La escucha al otro. No olvidemos que la escucha no es simple medio de conexión con el mundo exterior, sino que es condición para la acción e incluso es ya un tipo de acción. Asimismo, la escucha es relación, apertura a una nueva sensibilidad y transformación personal. El libro concluye con un epílogo donde el autor se pregunta: ¿no es esta ética un producto extranjero más que los pueblos latinoamericanos, y el peruano en particular, no está llamado a recorrer? Miguel Polo considera que una de las grandes dificultades en los seres humanos son las etiquetas desde las cuales nos definimos y juzgamos: peruanos, argentinos, venezolanos, norteamericanos, europeos, africanos orientales, etc. Dichas etiquetas son engañosas y encubren relaciones complejas de dominación y discriminación. Para el autor, debemos pensarnos como humanidad que coopera y solidariza porque tenemos más semejanzas que diferencias: las guerras, hambre, el cambio climático, la devastación de la naturaleza, etc. Para finalizar, subraya que la ética del autoconocimiento "no es un mero ensimismamiento" o huida frente a la desenfrenada mentalidad capitalista 
que lo reduce todo al placer, ganancia, individualismo. Podría aplicarse a la política y, de este modo, aprender a escuchar las demandas de las personas y poblaciones, antes que estar motivados por ideología o intereses. Es necesario “ir más allá de nuestras pequeñas pertenencias identitarias y abrir la mente y el corazón a otros aspectos que van más allá de la mente egocéntrica” (p. 108).

\section{Segundo Montoya Huamaní}

Universidad Nacional Mayor de San Marcos

Contacto: segundo.montoya@unmsm.edu.pe https://orcid.org/0000-0003-3963-6471 